\title{
OPTIMAL ORDER POLICY FOR DETERIORATING ITEMS IN RESPONSE TO TEMPORARY PRICE DISCOUNT LINKED TO ORDER QUANTITY
}

\author{
LIANG-YUH OUYANG, CHIH-TE YANG AND HSIU-FENG YEN
}

\begin{abstract}
This paper investigates the possible effects of a temporary price discount offered by a supplier on a retailer's replenishment policy for deteriorating items, whereby the price discount rate depends on the order quantity. The purpose of this study is to develop a decision process for retailers to assist in determining whether to adopt a regular or special order policy. Furthermore, the optimal quantity of a special order policy for a selected case is determined by maximizing the total cost saving between special and regular orders for the duration of the depletion time. This research establishes an algorithm to determine the optimal solution and utilizes several numerical examples to illustrate the theoretical results and subsequently conducts a sensitivity analysis of the optimal solution with respect to the main parameters. Finally, the results reveal that (1) the optimal special order quantity is determined by trading off the benefits of the price discount against the additional holding cost, (2) the retailer benefits in terms of total cost saving if the remnant inventory is as low as possible when adopting a special order policy, (3) for the retailer it is preferable to adopt the special order policy if the unit purchase cost, market demand rate and/or ordering cost increase, and (4) the retailer will order a lower quantity and the total cost saving will decrease when either the holding cost rate or deterioration rate is high. Thus, this study provides the basis for enterprises to make inventory decisions.
\end{abstract}

\section{Introduction}

The most common practical method for the supplier to stimulate demand, increase market share and cash flow, whilst reducing its inventory of specific items is to offer a temporary price discount to retailers. When the supplier offers a temporary price discount for any of the above reasons, it is important for the retailer to determine whether or not it is advantageous to place a special forward buying order (i.e., purchase additional stock at the reduced price offered by the supplier for a delayed sale at the regular selling price). Several researchers have studied temporary price discounts and proposed various inventory models to gain deeper insight into the relationship between price discounts

Corresponding author: Liang-Yuh Ouyang.

Key words and phrases. Inventory, temporary price discount, deteriorating item. 
and order policy. Naddor [1], Barker [2], and Tersine [3] were the earliest researchers to propose inventory models in response to a temporary price discount where the special sale coincides with the replenishment time. Following this, Barker and Vilcassim [4], Goyal [5], Tersine [6], and Silver et al. [7] studied situations where the special sale occurs during the retailer's sales period. Ardalan [8,9] developed optimal order policies with possible combinations of replenishment times and sales periods. Martin [10] modified Tersine's [6] model and claimed to reveal a flaw in its formulation regarding the calculation of the average inventory of a regular policy. Goyal [11] rebuffed Martin [10] and demonstrated that no flaw existed in Tersine's [6] methods for calculating the average inventory of a regular policy. More research studying the response to a temporary sale price include Aull-Hyde [12], Abad [13], Bhaba and Mahmood [14], Abad [15], Lev et al. [16], Tersine and Gengler [17], Davis and Gaither [18], Wee and Yu [19], Chang and Dye [20], Arcelus et al. [21], Bhavin [22], Dye et al. [23], and so on.

In the above inventory literature about temporary price discounts, all researchers assumed that the price discount rate is independent of the special order quantity. However, in practical business situations, the supplier usually proposes a quantity discount to encourage larger orders. Specifically, the larger the quantity the retailer orders, the higher the price discount rate provided by the supplier. As a result, the retailer may trade off purchase price savings against higher total carrying cost. As to the research considering quantity discount, Lal and Staelin [24] presented a model of buyer reaction to seller pricing schemes which assumed special forms of discount price structure with multiple buyers and constant demands. Weng and Wong [25] developed general all-unit quantity discount models for a single buyer or multiple buyers. Their analysis provides methods for simultaneously determining the optimal decision policies. Other recent studies related to the quantity discount recently included Shiue [26], Burwell et al. [27], Wee [28], Papachristos and Skouri [29], etc. The above inventory models mainly discuss the development of the quantity discount policies. However, one weakness common to most inventory models is that they neglect to consider the effects of temporary price discounts.

In addition, inventory problems for deteriorating items have been widely studied in recent years: It is well known that certain products, such as medicine, volatile liquids, blood, fruit and vegetables perish with time and therefore the on-hand inventory reduces during their normal storage period. For such types of products, if the retailer ignores the losses due to deterioration, they will make wrong inventory decisions. In relevant literature, inventory problems relating to deteriorating items have been studied widely. Ghare and Schrader [30] first established an economic order quantity (EOQ) model for an exponentially-decaying item, for which there is constant demand. Later, Covert and Philip [31] extended Ghare and Scharder's [30] model and obtained an EOQ model for a variable deterioration rate, by assuming a two-parameter Weibull distribution. Philip [32] then developed an inventory model with a three-parameter Weibull distribution deterioration rate. Shah [33] extended Philip's [32] model and considered the circumstances in which a shortage is allowed. Recently, Goyal and Giri [34] provided an excellent and detailed review of the deteriorating inventory literature since the early 1990s. Furthermore, there is also a vast amount of literature on deteriorating items. An outline of which can be found by reviewing Moon et al. [35], Deng et al. [36], Liao [37] and others. 
In this paper, we investigate the possible effects of a temporary price discount on a retailer's replenishment policy for deteriorating items, where the price discount rate links to the special order quantity. The purpose of this study is to develop a decision process to assist retailers in deciding whether to adopt a regular or special order policy. For the case where a special order policy is selected, the retailer's optimal special order quantity is determined by maximizing the total cost saving between special and regular orders during a special order period. In addition, the special order time may or may not coincide with the replenishment time. Hence, there are two possible situations investigated: the special order time occurs (i) at the retailer's replenishment time, and (ii) during the retailer's sales period. The theoretical analysis is conducted and the results categorizing the optimal solutions are presented for each of the two scenarios. Furthermore, an algorithm is established to determine the optimal solutions. Finally, several numerical examples are given to illustrate the theoretical results, followed by a sensitivity analysis of the optimal solution with respect to the main parameters.

\section{Notation and assumptions}

The following notation and assumptions are used in this study:

\section{Notation}

$D=$ market demand rate.

$c=$ unit purchasing price.

$A=$ ordering cost per regular or special order.

$r=$ holding cost rate.

$\theta=$ deterioration rate, where $0 \leq \theta<1$, and is a constant.

$Q=$ order quantity under regular order policy.

$Q^{*}=$ optimal order quantity under regular order policy.

$T=$ length of replenishment cycle time under regular order policy.

$T^{*}=$ optimal length of replenishment cycle time under regular order policy.

$Q_{s}=$ special order quantity at discount price, decision variable.

$T_{s}=$ length of depletion time for the special order quantity $Q_{s}$.

$q=$ inventory level before the special order quantities arrive, where $q>0$.

$t_{q}=$ length of depletion time for the inventory level $q$, where $t_{q}=\frac{1}{\theta} \ln \left(\frac{\theta q}{D}+1\right)$.

$T_{W}=$ length of depletion time for the inventory level $W=Q_{s}+q$.

$I(t)=$ inventory level at time $t$ when adopt the regular order policy, $0 \leq t \leq T$.

$I_{s}(t)=$ inventory level at time $t$ when the special order policy is adopted, $0 \leq t \leq T_{s}$.

$I_{W}(t)=$ inventory level at time $t$ when the special order policy is adopted, $0 \leq t \leq W$, where $W=Q_{s}+q$. 


\section{Assumptions}

1. The supplier offers the retailer a temporary price discount as the order quantity is larger than the regular order quantity $Q^{*}$. Moreover, the discount rate depends on the quantity ordered and the discount schedule, as follows:

\begin{tabular}{ccc}
\hline Classification & Special order quantity & Discount rate \\
$i$ & $Q_{s}$ & $\delta_{i}$ \\
\hline 1 & $w_{1} \leq Q_{s}<w_{2}$ & $\delta_{1}$ \\
2 & $w_{2} \leq Q_{s}<w_{3}$ & $\delta_{2}$ \\
$\vdots$ & $\vdots$ & $\vdots$ \\
$m$ & $w_{m} \leq Q_{s}<w_{m+1}$ & $\delta_{m}$ \\
\hline
\end{tabular}

where $w_{i}$ is the $i$ th discount rate breaking point, $i=1,2, \ldots, m+1$, and $Q^{*}<$ $w_{1}<w_{2}<\cdots<w_{m+1}=\infty ; \delta_{i}$ is the price discount fraction offered by the supplier, when the retailer's order quantity $Q_{s}$ belongs to the interval $\left[w_{i}, w_{i+1}\right)$, and $0<\delta_{1}<\delta_{2}<\cdots<\delta_{m}$.

2. The temporary discount occurs at only one instance in time.

3. The replenishment rate is infinite and the lead time is zero.

4. Shortages are not allowed.

5. There is no replacement or repair for deteriorated units during the period under consideration.

6. None of the price discount is passed on to customers.

\section{Model formulation}

This paper investigates the possible effects of a temporary price discount being offered by the supplier on the retailer's replenishment policy, given that the commodity is deteriorating and the discount rate depends on the quantity ordered. As the retailer follows the regular order policy without a temporary price discount, they adopt a simple EOQ model with deteriorating items. In this situation, the depletion of the inventory occurs due to the combined effects of demand and physical deterioration. Hence, the change in inventory level can be illustrated by the following differential equation:

$$
\frac{d I(t)}{d t}=-\theta I(t)-D, \quad 0<t<T
$$

Given the boundary condition $I(T)=0$, the solution of (1) may be represented by

$$
I(t)=\frac{D}{\theta}\left[e^{\theta(T-t)}-1\right], \quad 0 \leq t \leq T .
$$


Thus, the order quantity is given by

$$
Q=I(0)=\frac{D}{\theta}\left(e^{\theta T}-1\right)
$$

When the supplier does not offer the temporary price discount, the retailer follows the regular order policy with a unit purchasing cost $c$, and the total cost per order cycle is the sum of the ordering cost, purchasing cost and holding cost, that is

$$
A+c Q+r c \int_{0}^{T} I(t) d t=A+\frac{c D}{\theta}\left(e^{\theta T}-1\right)+\frac{r c D}{\theta^{2}}\left(e^{\theta T}-\theta T-1\right) .
$$

Therefore, the total cost per unit time without temporary price discount (denoted by $T C(T))$ is

$$
T C(T)=\frac{1}{T}\left[A+\frac{c D}{\theta}\left(e^{\theta T}-1\right)+\frac{r c D}{\theta^{2}}\left(e^{\theta T}-\theta T-1\right)\right] .
$$

It can be easily shown that $T C(T)$ is a convex function of $T$ (the proof is similar to that in Dye et al., [23] and we omit it here). Hence, there exists a unique value of $T$ (say $\left.T^{*}\right)$ that minimizes $T C(T) . T^{*}$ can be found by solving the equation $d T C(T) / d T=0$, i.e., $T^{*}$ satisfies the following equation:

$$
A-\frac{(\theta+r) c D}{\theta^{2}}\left(\theta T e^{\theta T}-e^{\theta T}+1\right)=0 .
$$

Once the optimal length of replenishment cycle time, $T^{*}$, is obtained, the optimal order quantity without a temporary price discount, $Q^{*}$, is obtained as follows:

$$
Q^{*}=\frac{D}{\theta}\left(e^{\theta T^{*}}-1\right) .
$$

When the supplier offers a temporary price discount, the retailer may order a quantity which is greater than $Q^{*}$ to take advantage of the discount price. Alternatively, the retailer may ignore this notice and adopt a regular order policy without the price discount. The purpose of this study is to determine the optimal special order quantity by maximizing the total cost saving between special and regular orders during the length of depletion time for the special order quantity. As stated earlier, two specific situations discussed in this study are: (1) when the special order time occurs at the retailer's replenishment time; and (2) when the special order time occurs during the retailer's sales period. In the next section of this paper, we formulate the corresponding total cost saving function for these two cases.

\section{Case 1: The special order time occurs at the retailer's replenishment time}

In this case, if the retailer decides to adopt a special order policy and orders $Q_{s}$ units, similarly to the formulation for items without price discount, the inventory level at time $t$ is

$$
I_{s}(t)=\frac{D}{\theta}\left[e^{\theta\left(T_{s}-t\right)}-1\right], \quad 0 \leq t \leq T_{s},
$$


and the special order quantity is

$$
Q_{s}=I_{s}(0)=\frac{D}{\theta}\left(e^{\theta T_{s}}-1\right)
$$

Due to the price discount rate being dependent on the special order quantity, for the given price discount rate $\delta_{i}$, the total cost of the special order during the time interval $\left[0, T_{s}\right]$ (denoted by $T C S_{1 i}\left(T_{s}\right)$ ) consists of the ordering cost $A$, purchasing cost $\left(1-\delta_{i}\right) c Q_{s}=$ $\left(1-\delta_{i}\right) c D\left(e^{\theta T_{s}}-1\right) / \theta$ and holding cost $\left(1-\delta_{i}\right) r c D\left(e^{\theta T_{s}}-\theta T_{s}-1\right) / \theta^{2}$, that is

$$
T C S_{1 i}\left(T_{s}\right)=A+\frac{\left(1-\delta_{i}\right) c D}{\theta}\left(e^{\theta T_{s}-1}\right)+\frac{\left(1-\delta_{i}\right) r c D}{\theta^{2}}\left(e^{\theta T_{s}}-\theta T_{s}-1\right) .
$$

On the other hand, if the retailer adopts its regular order policy (i.e., order quantity is $Q^{*}$ ) instead of placing a large special order policy, then the total cost during the time interval $\left[0, T_{s}\right]$ can be obtained by using the average cost approach (see Figure 1 ) which was asserted by Tersine [6], and used by Goyal [11]. That is, the total cost of a regular order during the time interval $\left[0, T_{s}\right]$ (denoted by $T C N_{1}\left(T_{s}\right)$ ) is

$$
T C N_{1}\left(T_{s}\right)=\frac{T_{s}}{T^{*}}\left[A+\frac{c D}{\theta}\left(e^{\theta T^{*}}-1\right)+\frac{r c D}{\theta^{2}}\left(e^{\theta T^{*}}-\theta T^{*}-1\right)\right]
$$

Comparing (10) with (11), for the fixed price discount rate $\delta_{i}$, the total cost saving

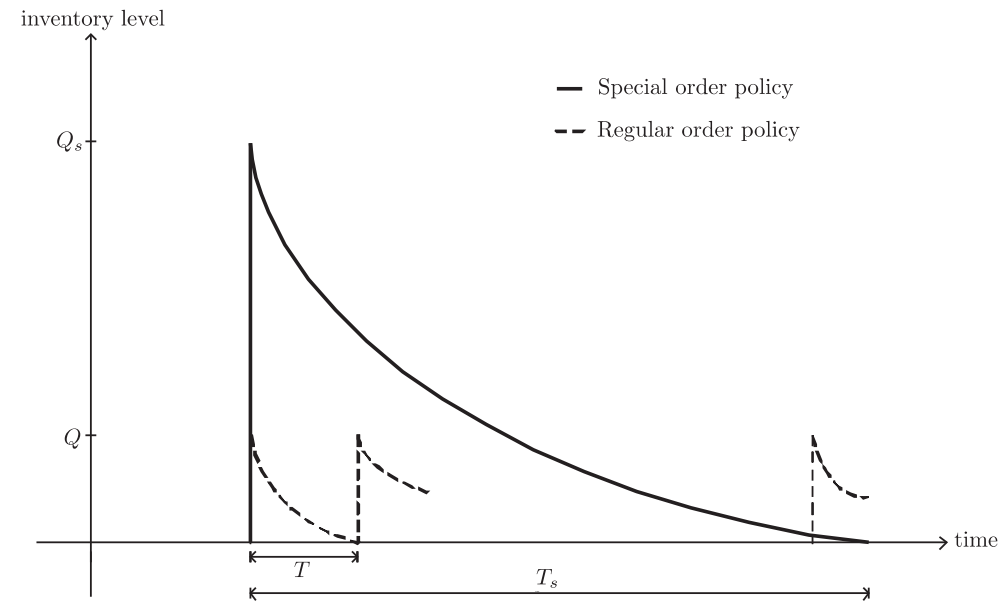

Figure 1. Special vs. regular order policies when the special order time coincides with the retailer's replenishment time. 
(denoted by $g_{1 i}\left(T_{s}\right)$ ) can be formulated as follows:

$$
\begin{aligned}
g_{1 i}\left(T_{s}\right)= & T C N_{1}\left(T_{s}\right)-T C S_{1 i}\left(T_{s}\right) \\
= & \frac{T_{s}}{T^{*}}\left[A+\frac{c D}{\theta}\left(e^{\theta T^{*}}-1\right)+\frac{r c D}{\theta^{2}}\left(e^{\theta T^{*}}-\theta T^{*}-1\right)\right] \\
& -A-\frac{\left(1-\delta_{i}\right) c D}{\theta}\left(e^{\theta T_{s}}-1\right)-\frac{\left(1-\delta_{i}\right) r c D}{\theta^{2}}\left(e^{\theta T_{s}}-\theta T_{s}-1\right) .
\end{aligned}
$$

\section{Case 2: The special order time occurs during the retailer's sales period}

The price discount offered by the supplier may occur during the retailer's sales period. In this situation, if the retailer decides to place a special order quantity $Q_{s}$ with the discount price $\left(1-\delta_{i}\right) c$, where $\delta_{i}$ is given, then the inventory level will increase instantaneously from $q$ to $W=Q_{s}+q$ when the special order quantities are delivered (see Figure 2 ). Otherwise, if the retailer ignores notice of the price discount, then they will not place any order until the next replenishment. We will formulate the total cost functions for the special and regular order policies and then compare them to each other.

When a special order is placed, the total cost during the time interval $\left[0, T_{W}\right]$ consists of the ordering cost $A$, the purchasing cost $\left(1-\delta_{i}\right) c Q_{s}=\left(1-\delta_{i}\right) c D\left(e^{\theta T_{s}}-1\right) / \theta$, and the holding cost which can be presented as follows:

As the special order quantities arrive, the stock on hand increases instantaneously

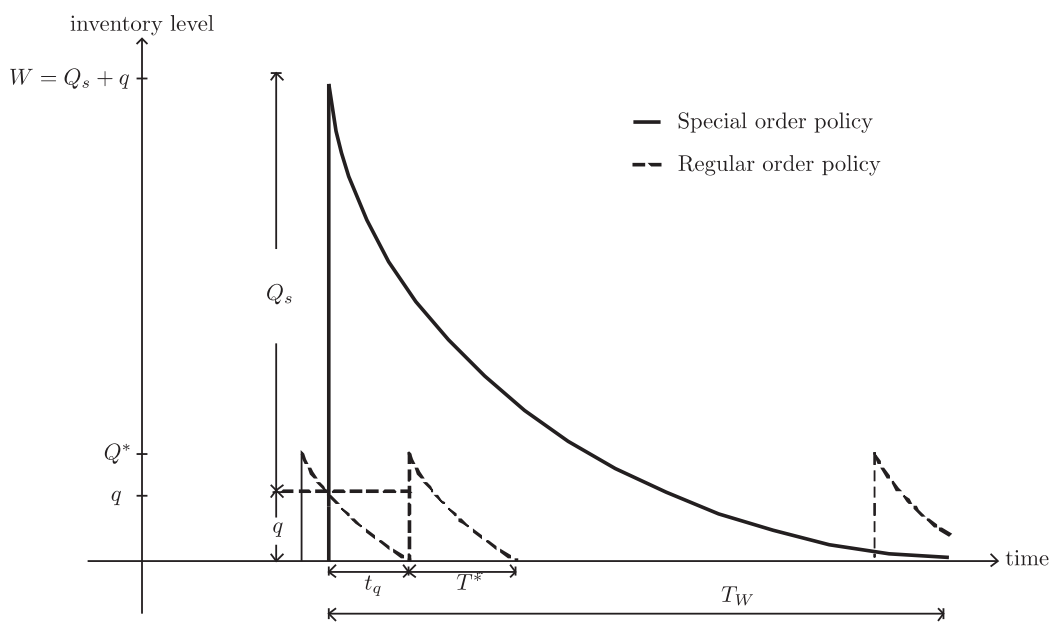

Figure 2. Special vs. regular order policies when the special order time occurs during the retailer's sales period. 
from $q$ to $W$, where

$$
\begin{aligned}
W & =Q_{s}+q \\
& =\frac{D}{\theta}\left(e^{\theta T_{s}}-1\right)+\frac{D}{\theta}\left(e^{\theta t_{q}}-1\right) \\
& =\frac{D}{\theta}\left(e^{\theta T_{s}}+e^{\theta t_{q}}-2\right) .
\end{aligned}
$$

And the inventory level at time $t$ during the time interval $\left[0, T_{W}\right]$ can be found by

$$
I_{W}(t)=\frac{D}{\theta}\left[e^{\theta\left(T_{W}-t\right)}-1\right], \quad 0 \leq t \leq T_{W}
$$

Because $I_{W}(0)=W$, from (13) and (14), it gives

$$
\frac{D}{\theta}\left(e^{\theta T_{W}}-1\right)=\frac{D}{\theta}\left(e^{\theta T_{s}}+e^{\theta t_{q}}-2\right) .
$$

Thus,

$$
T_{W}=\frac{1}{\theta} \ln \left(e^{\theta T_{s}}+e^{\theta t_{q}}-1\right) .
$$

The holding cost of the remnant $q$ is calculated with the unit purchasing cost $c$ and is given by $r c D\left(e^{\theta t_{q}}-\theta t_{q}-1\right) / \theta^{2}$. Besides, the holding cost of the order quantity $Q_{s}$ can be calculated with the unit purchasing cost $\left(1-\delta_{i}\right) c$ and is given by

$$
\begin{aligned}
& \left(1-\delta_{i}\right) r c\left[\int_{0}^{T_{W}} I_{W}(t) d t-\frac{D}{\theta^{2}}\left(e^{\theta t_{q}}-\theta t_{q}-1\right)\right] \\
& \quad=\frac{\left(1-\delta_{i}\right) r c D}{\theta^{2}}\left[e^{\theta T_{s}}+e^{\theta t_{q}}-2-\ln \left(e^{\theta T_{s}}+e^{\theta t_{q}}-1\right)-\left(e^{\theta t_{q}}-\theta t_{q}-1\right)\right] .
\end{aligned}
$$

Therefore, the total holding cost during the time interval $\left[0, T_{W}\right]$ is

$$
\begin{aligned}
& \frac{r c D\left(e^{\theta t_{q}}-\theta t_{q}-1\right)}{\theta^{2}}+\frac{\left(1-\delta_{i}\right) r c D}{\theta^{2}}\left[e^{\theta T_{s}}+e^{\theta t_{q}}-2\right. \\
& \left.-\ln \left(e^{\theta T_{s}}+e^{\theta t_{q}}-1\right)-\left(e^{\theta t_{q}}-\theta t_{q}-1\right)\right] \\
& =\frac{\left(1-\delta_{i}\right) r c D}{\theta^{2}}\left[e^{\theta T_{s}}+e^{\theta t_{q}}-2-\ln \left(e^{\theta T_{s}}+e^{\theta t_{q}}-1\right)\right] \\
& +\frac{\delta_{i} r c D}{\theta^{2}}\left(e^{\theta t_{q}}-\theta t_{q}-1\right) .
\end{aligned}
$$

Consequently, for the fixed price discount rate $\delta_{i}$, the total cost of the special order during the time interval $\left[0, T_{W}\right]$ (denoted by $T C S_{2 i}\left(T_{s}\right)$ ) can be formulated as follows:

$$
\begin{aligned}
T C S_{2 i}\left(T_{s}\right)= & A+\frac{\left(1-\delta_{i}\right) c D}{\theta}\left(e^{\theta T_{s}}-1\right)+\frac{\left(1-\delta_{i}\right) r c D}{\theta^{2}}\left[e^{\theta T_{s}}+e^{\theta t_{q}}-2\right. \\
& \left.-\ln \left(e^{\theta T_{s}}+e^{\theta t_{q}}-1\right)\right]+\frac{\delta_{i} r c D}{\theta^{2}}\left(e^{\theta t_{q}}-\theta t_{q}-1\right) .
\end{aligned}
$$


On the other hand, if the retailer ignores notification of the price discount and fails to place an order until the next replenishment, and follows its regular order policy, the total cost during the time interval $\left[0, T_{W}\right]$ will also be divided into two periods. In the first period, the retailer only has the remnant $q$ and the holding cost is

$$
r c \int_{0}^{t_{q}} I(t) d t=\frac{r c D}{\theta^{2}}\left(e^{\theta t_{q}}-\theta t_{q}-1\right) .
$$

Next, the retailer follows the regular order policy (i.e., the order quantity is $Q^{*}$ ) during the rest period. To obtain the total cost in this period, we use the average cost analysis approach, which is given by

$$
\begin{aligned}
& \frac{T_{W}-t_{q}}{T^{*}}\left[A+\frac{c D}{\theta}\left(e^{\theta T^{*}}-1\right)+\frac{r c D}{\theta^{2}}\left(e^{\theta T^{*}}-\theta T^{*}-1\right)\right] \\
& =\frac{\ln \left(e^{\theta T_{s}}+e^{\theta t_{q}}-1\right)-\theta t_{q}}{\theta T^{*}}\left[A+\frac{c D}{\theta}\left(e^{\theta T^{*}}-1\right)+\frac{r c D}{\theta^{2}}\left(e^{\theta T^{*}}-\theta T^{*}-1\right)\right] .
\end{aligned}
$$

As a result, if the retailer ignores the notification and follows its regular order policy during the time interval $\left[0, T_{W}\right]$, the total cost (denoted by $T C N_{2}\left(T_{s}\right)$ ) is represented by:

$$
\begin{aligned}
\operatorname{TCN}_{2}\left(T_{s}\right)= & \frac{r c D}{\theta^{2}}\left(e^{\theta t_{q}}-\theta t_{q}-1\right)+\frac{\ln \left(e^{\theta T_{s}}+e^{\theta t_{q}}-1\right)-\theta t_{q}}{\theta T^{*}} \\
& \times\left[A+\frac{c D}{\theta}\left(e^{\theta T^{*}}-1\right)+\frac{r c D}{\theta^{2}}\left(e^{\theta T^{*}}-\theta T^{*}-1\right)\right] .
\end{aligned}
$$

Therefore, for a fixed price discount $\delta_{i}$, the total cost saving (denoted by $g_{2 i}\left(T_{s}\right)$ ) when the special order time occurs during the retailer's sales period can be formulated as follows:

$$
\begin{aligned}
g_{2 i}\left(T_{s}\right)= & T C N_{2}\left(T_{s}\right)-T C S_{2 i}\left(T_{S}\right) \\
= & {\left[\frac{1}{\theta} \ln \left(e^{\theta T_{s}}+e^{\theta t_{q}}-1\right)-t_{q}\right]\left\{\frac{1}{T^{*}}\left[A+\frac{c D}{\theta}\left(e^{\theta T^{*}}-1\right)+\frac{r c D}{\theta^{2}}\left(e^{\theta T^{*}}-\theta T^{*}-1\right)\right]\right.} \\
& \left.+\frac{\left(1-\delta_{i}\right) r c D}{\theta}\right\}-A-\frac{\left(1-\delta_{i}\right)(\theta+r) c D}{\theta^{2}}\left(e^{\theta T_{s}}-1\right) .
\end{aligned}
$$

Note that it is worth placing a special order when the total cost saving in (12) and (21) are positive for the above two cases. Otherwise, the special order policy will be ignored by the retailer.

\section{Theoretical results}

In this section, the optimal value of $T_{s}$ that maximizes the total cost saving is determined. 
Case 1: The special order time occurs at the retailer's replenishment time

For the fixed price discount rate $\delta_{i}$, taking the first and second order derivatives of $g_{1 i}\left(T_{s}\right)$ in $(12)$ with respect to $T_{s}$, leads to

$$
\begin{aligned}
\frac{d g_{1 i}\left(T_{s}\right)}{d T_{s}}= & \frac{1}{T^{*}}\left[A+\frac{c D}{\theta}\left(e^{\theta T^{*}}-1\right)+\frac{r c D}{\theta^{2}}\left(e^{\theta T^{*}}-\theta T^{*}-1\right)\right] \\
& -\left(1-\delta_{i}\right) c D e^{\theta T_{s}}-\frac{\left(1-\delta_{i}\right) r c D}{\theta}\left(e^{\theta T_{s}}-1\right),
\end{aligned}
$$

and

$$
\frac{d^{2} g_{1 i}\left(T_{s}\right)}{d T_{s}^{2}}=-(\theta+r)\left(1-\delta_{i}\right) c D e^{\theta T_{s}}<0 .
$$

Consequently, $g_{1 i}\left(T_{s}\right)$ is a concave function of $T_{s}$; hence, a unique value of $T_{s}$ (say $T_{s_{1 i}}$ ) exists that maximizes $g_{1 i}\left(T_{s}\right) . \quad T_{s_{1 i}}$ and can be found by solving the equation $d g_{1 i}\left(T_{s}\right) / d T_{s}=0$. Given by

$$
T_{s_{1 i}}=\frac{1}{\theta} \ln \left[\frac{\left(1-\delta_{i}\right) r c D+\theta y}{(\theta+r)\left(1-\delta_{i}\right) c D}\right]
$$

where $y=\frac{1}{T^{*}}\left[A+\frac{c D}{\theta}\left(e^{\theta T^{*}}-1\right)+\frac{r c D}{\theta^{2}}\left(e^{\theta T^{*}}-\theta T^{*}-1\right)\right]>0$.

To ensure $Q^{*}<Q_{s_{1 i}}$ (i.e., $T^{*}<T_{s_{1 i}}$, where $T^{*}$ can be found by solving Equation (6)), we substitute $(24)$ into the inequality $T^{*}<T_{s_{1 i}}$, and it results in

$$
\text { if } \Delta_{1 i}>0 \text {, then } T^{*}<T_{s_{1 i}} \text {, }
$$

where $\Delta_{1 i} \equiv y-\left(1-\delta_{i}\right) c D e^{\theta T^{*}}-\frac{\left(1-\delta_{i}\right) r c D}{\theta}\left(e^{\theta T^{*}}-1\right)$.

Next, substituting (24) into (12), the corresponding maximum total cost saving can be obtained as

$$
g_{1 i}\left(T_{s_{1 i}}\right)=\frac{(\theta+r)\left(1-\delta_{i}\right) c D}{\theta^{2}}\left(\theta T_{s_{1 i}} e^{\theta T_{s_{1 i}}}-e^{\theta T_{s_{1 i}}}+1\right)-A .
$$

It is worth placing a special order only if $g_{1 i}\left(T_{s_{1 i}}\right)>0$. Otherwise, the retailer will adopt the regular order policy (i.e., the order quantity is $Q^{*}$ ). Let

$$
\Delta_{2 i} \equiv g_{1 i}\left(T_{s_{1 i}}\right)=\frac{(\theta+r)\left(1-\delta_{i}\right) c D}{\theta^{2}}\left(\theta T_{s_{1 i}} e^{\theta T_{s_{1 i}}}-e^{\theta T_{s_{1 i}}}+1\right)-A,
$$

then from the above arguments, we can obtain the optimal value of $T_{s_{1 i}}$ (denoted by $\left.T_{s_{1 i}}^{*}\right)$ for the Case 1 as follows:

$$
T_{s_{1 i}}^{*}= \begin{cases}T_{s_{1 i}}, & \text { if } \Delta_{1 i}>0 \text { and } \Delta_{2 i}>0 \\ T^{*}, & \text { otherwise. }\end{cases}
$$


Remark 1. When the optimal length of depletion time for the special order quantity is $T_{s_{1 i}}^{*}=T^{*}$, it means that it is not worthwhile for the retailer to place a special order; instead, the retailer should adopt its regular order policy with the original unit purchasing cost $c$.

\section{Case 2: The special order time occurs during the retailer's sales period}

Similarly, for the fixed price discount rate $\delta_{i}$, the first order necessary condition for $g_{2 i}\left(T_{s}\right)$ in $(21)$ to be maximized is

$$
\frac{d g_{2 i}\left(T_{s}\right)}{d T_{s}}=\left(y+\frac{\left(1-\delta_{i}\right) r c D}{\theta}\right) \frac{e^{\theta T_{s}}}{e^{\theta T_{s}}+e^{\theta t_{q}}-1}-\frac{(\theta+r)\left(1-\delta_{i}\right) c D e^{\theta T_{s}}}{\theta}=0 .
$$

Solving this equation, we can obtain a unique solution for $T_{s}\left(\right.$ say $T_{s_{2 i}}$ ) as

$$
T_{s_{2 i}}=\frac{1}{\theta} \ln \left[\frac{\theta y+\left(1-\delta_{i}\right) r c D-(\theta+r)\left(1-\delta_{i}\right) c D\left(e^{\theta t_{q}}-1\right)}{(\theta+r)\left(1-\delta_{i}\right) c D}\right] .
$$

Furthermore, we can show that

$$
\begin{aligned}
\left.\frac{d^{2} g_{2 i}\left(T_{s}\right)}{d T_{s}^{2}}\right|_{T_{s}=T_{s_{2 i}}} & =\left(y+\frac{\left(1-\delta_{i}\right) r c D}{\theta}\right) \frac{\theta e^{\theta T_{s_{2 i}}}\left(e^{\theta t_{q}}-1\right)}{\left(e^{\theta T_{s_{2 i}}}+e^{\theta t_{q}}-1\right)^{2}}-\left(1-\delta_{i}\right)(\theta+r) c D e^{\theta T_{s_{2 i}}} \\
& =-\frac{\left(1-\delta_{i}\right)(\theta+r) c D e^{2 \theta T_{s_{2 i}}}}{e^{\theta T_{s_{2 i}}}+e^{\theta t_{q}}-1}<0 .
\end{aligned}
$$

Hence, $T_{s_{2 i}}$ in (29) is the optimal solution for $T_{s}$, which maximizes $g_{2 i}\left(T_{s}\right)$.

Next, to ensure that $Q^{*}<Q_{s_{2 i}}$ (i.e., $T^{*}<T_{s_{2 i}}$ ), we substitute (29) into this inequality, which results in

$$
\text { if } \Delta_{3 i}>0 \text {, then } T^{*}<T_{s_{2 i}} \text {, }
$$

where

$$
\Delta_{3 i} \equiv y-\frac{(\theta+r)\left(1-\delta_{i}\right) c D}{\theta}\left(e^{\theta T^{*}}+e^{\theta t_{q}}-1\right)+\frac{\left(1-\delta_{i}\right) r c D}{\theta} .
$$

Furthermore, substituting (29) into (21), the corresponding maximum total cost saving can be obtained as

$$
\begin{aligned}
g_{2 i}\left(T_{s_{2 i}}\right)= & \frac{(\theta+r)\left(1-\delta_{i}\right) c D}{\theta^{2}}\left[\ln \left(e^{\theta T_{s}}+e^{\theta t_{q}}-1\right)-\theta t_{q}\right]\left(e^{\theta T_{s}}+e^{\theta t_{q}}-1\right) \\
& -\frac{(\theta+r)\left(1-\delta_{i}\right) c D}{\theta^{2}}\left(e^{\theta T_{s}}-1\right)-A .
\end{aligned}
$$

As we know, it is worthwhile placing a special order only if $g_{2 i}\left(T_{s_{2 i}}\right)>0$. Otherwise, the retailer will not order until the next replenishment time, following the regular order policy. Let

$$
\begin{aligned}
\Delta_{4 i}=g_{2 i}\left(T_{s_{2 i}}\right)= & \frac{(\theta+r)\left(1-\delta_{i}\right) c D}{\theta^{2}}\left[\ln \left(e^{\theta T_{s}}+e^{\theta t_{q}}-1\right)-\theta t_{q}\right]\left(e^{\theta T_{s}}+e^{\theta t_{q}}-1\right) \\
& -\frac{(\theta+r)\left(1-\delta_{i}\right) c D}{\theta^{2}}\left(e^{\theta T_{s}}-1\right)-A
\end{aligned}
$$


and then from the above arguments, we can obtain the optimal value of $T_{s}$ (denoted by $\left.T_{s_{2 i}}^{*}\right)$ for the Case 2 as follows:

$$
T_{s_{2 i}}^{*}= \begin{cases}T_{s_{2 i}}, & \text { if } \Delta_{3 i}>0 \text { and } \Delta_{4 i}>0, \\ 0, & \text { otherwise. }\end{cases}
$$

Remark 2. When the optimal length of depletion time for a special order quantity is $T_{s_{2 i}}^{*}=0$, the retailer should not order until the next replenishment time and thus follow the regular order quantity with the original unit purchasing $\operatorname{cost} c$.

To summarize the above results, we can develop an algorithm to obtain the optimal solution $T_{s}^{*}$ and the optimal order quantity $Q_{s}^{*}$, for the two cases.

\section{Algorithm:}

Step 1. If $q=0$, then determine $T^{*}$ from (6) and go to Step 2. Otherwise, calculate $t_{q}$ from the equation $q=D\left(e^{\theta t_{q}}-1\right) / \theta$, and go to Step 4 .

Step 2. For each $\delta_{i}, i=1,2, \ldots, m$, calculate $T_{s_{1 i}}$ in $(24), \Delta_{1 i} \equiv y-\left(1-\delta_{i}\right) c D e^{\theta T^{*}}-$ $\frac{\left(1-\delta_{i}\right) r c D}{\theta}\left(e^{\theta T^{*}}-1\right)$ and $\Delta_{2 i}=\frac{(\theta+r)\left(1-\delta_{i}\right) c D}{\theta^{2}}\left(\theta T_{s_{1 i}} e^{\theta T_{s_{1 i}}}-e^{\theta T_{s_{1 i}}}+1\right)-$ $A$. If $\Delta_{1 i}>0$ and $\Delta_{2 i}>0$, then substitute $T_{s_{1 i}}$ into (9) to evaluate the corresponding lot size, $Q_{s_{1 i}}$ and check $Q_{s_{1 i}}$ under $\delta_{i}$.

(i) If $w_{i} \leq Q_{s_{1 i}}<w_{i+1}, Q_{s_{1 i}}$ is a feasible solution. Set $Q_{s_{1 i}}^{*}=Q_{s_{1 i}}$ and substitute $T_{s_{1 i}}^{*}=T_{s_{1 i}}$ into (26) to evaluate $g_{1 i}\left(T_{s_{1 i}}^{*}\right)$.

(ii) If $Q_{s_{1 i}} \geq w_{i+1}$, we can get a larger price discount rate which is greater than $\delta_{i}$ and thus $Q_{s_{1 i}}$ is not a feasible solution. Set $g_{1 i}\left(T_{s_{1 i}}^{*}\right)=-\infty$.

(iii) If $Q_{s_{1 i}}<w_{i}$, set $Q_{s_{1 i}}^{*}=w_{i}$, and substitute $Q_{s_{1 i}}^{*}$ into (9) to find $T_{s_{1 i}}^{*}=$ $\frac{1}{\theta} \ln \left(\frac{\theta w_{i}}{D}+1\right)$. Then, substitute $T_{s_{1 i}}^{*}$ into $(26)$ to evaluate $g_{1 i}\left(T_{s_{1 i}}^{*}\right)$. If $g_{1 i}\left(T_{s_{1 i}}^{*}\right)>0$, go to Step 3 ; otherwise, set $T_{s_{1 i}}^{*}=T^{*}, Q_{s_{1 i}}^{*}=Q^{*}$ and $g_{1 i}\left(T_{s_{1 i}}^{*}\right)=0$.

Otherwise, set $T_{s_{1 i}}^{*}=T^{*}, Q_{s_{1 i}}^{*}=Q^{*}$ and $g_{1 i}\left(T_{s_{1 i}}^{*}\right)=0$.

Step 3. Find $\underset{i=1,2, \ldots, m}{\operatorname{Max}} g_{1 i}\left(T_{s_{1 i}}^{*}\right)$. If $g_{1 k}\left(T_{s_{1 k}}^{*}\right)=\underset{i=1,2, \ldots, m}{\operatorname{Max}} g_{1 i}\left(T_{s_{1 i}}^{*}\right), T_{s_{1 k}}^{*}$ is the optimal solution for Case 1 , and thus the optimal order quantity $Q_{s_{1 k}}^{*}$ can also be determined. Go to Step 6.

Step4. For each $\delta_{i}, i=1,2, \ldots, m$, calculate $T_{s_{2 i}}$ in (29),

$$
\begin{aligned}
\Delta_{3 i}= & y-\frac{(\theta+r)\left(1-\delta_{i}\right) c D}{\theta}\left(e^{\theta T^{*}}+e^{\theta t_{q}}-1\right)+\frac{\left(1-\delta_{i}\right) r c D}{\theta} \text { and } \\
\Delta_{4 i}= & \frac{(\theta+r)\left(1-\delta_{i}\right) c D}{\theta}\left[\ln \left(e^{\theta T_{s_{2 i}}}+e^{\theta t_{q}}-1\right)-\theta t_{q}\right]\left(e^{\theta T_{s_{2 i}}}+e^{\theta t_{q}}-1\right) \\
& -\frac{(\theta+r)\left(1-\delta_{i}\right) c D}{\theta^{2}}\left(e^{\theta T_{s_{2 i}}}-1\right)-A .
\end{aligned}
$$


If $\Delta_{3 i}>0$ and $\Delta_{4 i}>0$, then substitute $T_{s_{2 i}}$ into (13) to evaluate the corresponding lot size, $Q_{s_{2 i}}$ and check each $Q_{s_{2 i}}$ under $\delta_{i}$.

(i) If $w_{i} \leq Q_{s_{2 i}}<w_{i+1}, Q_{s_{2 i}}$ is a feasible solution. Set $Q_{s_{2 i}}^{*}=Q_{s_{2 i}}$ and substitute $T_{s_{2 i}}^{*}=T_{s_{2 i}}$ into (31) to evaluate $g_{2 i}\left(T_{s_{2 i}}^{*}\right)$.

(ii) If $Q_{s_{2 i}} \geq w_{i+1}$, we can get a larger price discount rate which is greater than $\delta_{i}$ and thus $Q_{s_{2 i}}$ is not a feasible solution. Set $g_{2 i}\left(T_{s_{2 i}}^{*}\right)=-\infty$.

(iii) If $Q_{s_{2 i}}<w_{i}$, set $Q_{s_{2 i}}^{*}=w_{i}$, and substitute $Q_{s_{2 i}}^{*}$ into (13), to find $T_{s_{2 i}}^{*}=$ $\frac{1}{\theta} \ln \left(\frac{\theta w_{i}}{D}+1\right)$. Then, substitute $T_{s_{2 i}}^{*}$ into (31) to evaluate $g_{2 i}\left(T_{s_{2 i}}^{*}\right)$. If $g_{2 i}\left(T_{s_{2 i}}^{*}\right)>0$, go to Step 5; otherwise, set $T_{s_{2 i}}^{*}=0, Q_{s_{2 i}}^{*}=0$ and $g_{2 i}\left(T_{s_{2 i}}^{*}\right)=0$.

Otherwise, set $T_{s_{2 i}}^{*}=0, Q_{s_{2 i}}^{*}=0$ and $g_{2 i}\left(T_{s_{2 i}}^{*}\right)=0$.

Step 5. Find $\underset{i=1,2, \ldots, m}{\operatorname{Max}} g_{2 i}\left(T_{s_{2 i}}^{*}\right)$. If $g_{2 k}\left(T_{s_{2 k}}^{*}\right)=\underset{i=1,2, \ldots, m}{\operatorname{Max}} g_{2 i}\left(T_{s_{2 i}}^{*}\right), T_{s_{2 k}}^{*}$ is the optimal solution for Case 2, and thus the optimal order quantity $Q_{s_{2 k}}^{*}$ can also be determined.

Step 6. Stop.

\section{Numerical examples}

To illustrate the solution process for the two cases, the following examples are presented.

Example 1. We first consider the case where the special order time occurs at the retailer's replenishment time. For a retailer with an inventory system with the following parameters: $c=\$ 10 /$ unit, $D=1000$ units/year, $A=\$ 150 /$ order, $r=0.3, \theta=0.01$. From the above data, the optimal solutions for the regular order quantity are ascertainable and are $T^{*}=0.3108$ and $Q^{*}=311.247$. Besides, the price discount rate schedule offered by the supplier is tabulated in Table 1. Using the algorithm, the solution procedure and computational results are shown in Table 2. From Table 2, we can see that the optimal order policy are as follows: $T_{s_{1}}^{*}=2.3717, Q_{s_{1}}^{*}=2400$ and $g_{1}^{*}=1476.70$.

Table 1. Price discount rate schedule.

\begin{tabular}{ccc}
\hline Classification & Special order quantity & Discount rate \\
$i$ & $Q_{s}$ & $\delta_{i}$ \\
\hline 1 & $500 \leq Q_{s}<1000$ & 0.1 \\
2 & $1000 \leq Q_{s}<2400$ & 0.15 \\
3 & $Q_{s} \geq 2400$ & 0.25 \\
\hline
\end{tabular}


Table 2. Optimal solutions of Example 1.

\begin{tabular}{ccccc}
\hline$\delta_{i}$ & $Q_{s_{1 i}}$ & $T_{s_{1 i}}^{*}$ & $Q_{s_{1 i}}^{*}$ & $g_{1 i}^{*}$ \\
\hline 0.10 & 704.25 & 0.6720 & 704.25 & 504.26 \\
0.15 & 935.43 & 0.9950 & 1000.00 & 993.84 \\
0.25 & 1490.26 & 2.3717 & 2400.00 & $1476.70 \leftarrow$ \\
\hline
\end{tabular}

Note: " $\leftarrow$ " denotes the maximum total cost saving.

Table 3. Optimal solutions of Example 2 under different values of $q$.

\begin{tabular}{cccc}
\hline$q$ & $Q_{s_{2}}^{*}$ & $T_{s_{2}}^{*}$ & $g_{2}^{*}$ \\
\hline 30 & 2400 & 2.3717 & 1310.84 \\
100 & 2400 & 2.3717 & 924.20 \\
200 & 1000 & 0.9905 & 468.22 \\
\hline
\end{tabular}

Example 2. In this example, we consider the case where the special order time occurs during the retailer's sales period. The data used are the same as those in Example 1 except for $q$. Three different values of $q$ are adapted, $q=30,100$, and 200. The optimal ordering policies under the various values of $q$ are listed in Table 3 .

From Table 3, it can be shown that the larger the level of remnant inventory $q$ (prior to the delivery of the special order quantity) is, the smaller the values of the total cost saving. This implies that it will be beneficial in terms of total cost savings for the remnant inventory to be as low as possible when the special order time occurs during the retailer's sales period.

Example 3. In this example, we study the effects of changes in system parameters $c, D$, $A, r$ and $\theta$ on the optimal price discount rate, special order quantity and the optimal total cost saving. The data used is the same as those in Example 2 except we only consider the case whereby $q=30$. To explore every situation, a sensitivity analysis is conducted by changing each of the parameters by the appropriate value taking one parameter at a time while all the other parameters remain unchanged. The results are shown in Table 4 .

On the basis of the results shown in Table 4, the following managerial insights are gained:

(1) The retailer will determine the optimal special order quantity by trading off the benefits of the price discount against the additional holding cost. For example, when $D=250$ or $\theta=0.8$ in Table 4 , the optimal order policy of retailer is to ignore the temporary price discount offered by the supplier and to refrain from ordering until the next replenishment time. Moreover, as the optimal order quantity is determined based on the maximum total cost saving, the optimal price discount rate is determined simultaneously. 
Table 4. Effect of changes in various parameters of the Example 3 (for $q=30$ ).

\begin{tabular}{|c|c|c|c|c|}
\hline Parameter & value & $\delta^{*}$ & $Q_{s_{2}}^{*}$ & $g_{2}^{*}$ \\
\hline \multirow{4}{*}{$c$} & 5.0 & 0.25 & 2400 & 1054.55 \\
\hline & 7.5 & 0.25 & 2400 & 1211.21 \\
\hline & 12.5 & 0.25 & 2400 & 1374.01 \\
\hline & 15.0 & 0.25 & 2400 & 1411.30 \\
\hline \multirow{4}{*}{$D$} & 250 & - & - & - \\
\hline & 500 & 0.10 & 500 & 250.13 \\
\hline & 750 & 0.15 & 1000 & 600.74 \\
\hline & 1250 & 0.25 & 2400 & 2422.11 \\
\hline \multirow{4}{*}{$A$} & 25.0 & 0.15 & 1000 & 471.79 \\
\hline & 37.5 & 0.25 & 1000 & 547.35 \\
\hline & 112.5 & 0.25 & 2400 & 1041.71 \\
\hline & 225.0 & 0.25 & 2400 & 1750.30 \\
\hline \multirow{4}{*}{$r$} & 0.15 & 0.25 & 2631 & 3966.43 \\
\hline & 0.25 & 0.25 & 2400 & 2207.73 \\
\hline & 0.35 & 0.15 & 1000 & 765.62 \\
\hline & 0.45 & 0.15 & 1000 & 452.98 \\
\hline \multirow{4}{*}{$\theta$} & 0.005 & 0.25 & 2400 & 1397.23 \\
\hline & 0.100 & 0.15 & 1000 & 345.38 \\
\hline & 0.500 & 0.10 & 500 & 124.79 \\
\hline & 0.800 & - & - & - \\
\hline
\end{tabular}

Note: "-" denotes the retailer will not order until the next replenishment time.

(2) When the unit purchase cost $c$, market demand rate $D$ and ordering cost $A$ increase, the total cost saving $g_{2}^{*}$ increases. The results show that as the unit purchase cost, market demand rate and ordering cost increase, it is more beneficial for the retailer to adopt the special order policy.

(3) When either $r$ or $\theta$ increases, $Q_{s_{2}}^{*}$ and $g_{2}^{*}$ decrease. It implies that when either the holding cost rate or deterioration rate is higher, the retailer will order a lower quantity and the total cost saving will decrease.

\section{Conclusions}

This study investigated the possible effects of a temporary price discount rate, which is linked to the special order quantity, on a retailer's replenishment policy. The purpose of this study was to determine the optimal order policy such that the total cost saving between special and regular order policies is maximized. By analyzing the total cost saving under special and regular order policies, results were developed to characterize 
the optimal solution. This research establishes an algorithm to determine the optimal solution and utilizes several numerical examples to illustrate the theoretical results and conducts a sensitivity analysis of the optimal solution with respect to the main parameters. Finally, the results reveal that (1) the optimal special order quantity is determined by trading off the benefits of the price discount against the additional holding cost, (2) the retailer benefits in terms of total cost saving if the remnant inventory is as low as possible when adopting a special order policy, (3) for the retailer, it is more beneficial to adopt the special order policy if the unit purchase cost, market demand rate and ordering cost increase, (4) the retailer will order a lower quantity and the total cost saving will decrease when either the holding cost rate or deterioration rate is high. Thus, this study provides the basis for enterprises to make inventory decisions.

The proposed model can be extended and further examined in several ways. Some suggestions include manipulating the proposed inventory model to consider the circumstances in which the retailer shifts the price discount to their customers and reformulating the demand rate so that it is a function of the sales price, holding time and remaining stock.

\section{References}

[1] E. Naddor, Inventory Systems, Wiley, New York, 1966, 96-102.

[2] R. C. Barker, Inventory policy for items on sale during regular replenishment, Production and Inventory Management 17 (1976), 55-64.

[3] R. J. Tersine, Principles of inventory and Materials Management, Ed. 2, North Holland, New York, 1982, 89-91.

[4] R. C. Barker and N. Vilcassim, Continuous review price change inventory model, Production and Inventory Management 24 (1983), 67-72.

[5] S. K. Goyal, Economic ordering policies during special discount periods for dynamic inventory problems under certainty, Engineering Costs and Production Economics 20 (1990), 101-104.

[6] R. J. Tersine, Principles of Inventory and Materials Management, Ed. 4, North Holland, New York, 1994, 113-117.

[7] E. A. Silver, D. F. Pyke and R. Peterson, Inventory Management and Production Planning and Scheduling, Wiley, New York, 1998, 174-179.

[8] A. Ardalan, Optimal ordering policies in response to a sale, IIE Transactions 20 (1988), 292-294.

[9] A. Ardalan, A comparative analysis of approaches for determining optimal price and order quantity when a sale increase demand, European Journal of Operational Research $\mathbf{8 4}$ (1995), 416-430.

[10] G. E. Martin, Note on an EOQ model with a temporary sale price, International Journal of Production Economics 37(1994), 241-243.

[11] S. K. Goyal, A comment on Martin's: Note on an EOQ model with a temporary sale price, International Journal of Production Economics 43 (1996), 283-284.

[12] R. L. Aull-Hyde, A backlog inventory model during restricted sale periods, Journal of the Operational Research Society 47 (1996), 1192-1200B. 
[13] P. L. Abad, Optimal policy for a reseller when the supplier offers a temporary reduction in price, Decision Sciences 28 (1997), 637-653.

[14] R. S. Bhaba and A. K. Mahmood, Optimal ordering policies in response to a discount offer, International Journal of Production Economics 100 (2006), 195-211.

[15] P. L. Abad, Buyer's response to a temporary price reduction incorporating freight costs, European Journal of Operational Research 182 (2007), 1073-1083.

[16] B. Lev, H. J. Weiss and A. L. Soyster, Optimal ordering policies when anticipating parameter changes in EOQ systems, Naval Research Logistics Quarterly 28 (1981), 267-279.

[17] R. J. Tersine and M. Gengler, Simplified forward buying with price changes, Journal of Purchasing and Materials Management 18 (1982), 27-32.

[18] R. A. Davis and N. Gaither, Optimal ordering policies under conditions of extended payment privileges, Management Science 31 (1985), 499-509.

[19] H. M. Wee and J. Yu, A deteriorating inventory model with a temporary price discount, International Journal of Production Economics 53 (1997), 81-90.

[20] H. J. Chang and C. Y. Dye, An EOQ model with deteriorating items in response to a temporary sale price, Production Planning \& Control 11 (2000), 464-473.

[21] F. J. Arcelus, H. Shah Nita and G. Srinivasan, Retailer's pricing, credit and inventory policies for deteriorating items in response to temporary price/credit incentives, International Journal of Production Economics 81-82 (2003), 153-162.

[22] J. S. Bhavin, EOQ model for time-dependent deterioration rate with a temporary price discount, Asia-Pacific Journal of Operational Research 22 (2005), 479-485.

[23] C. Y. Dye, H. J. Chang and C. H Wu, Purchase-inventory decision models for deteriorating items with a temporary sale price, International Journal of Information and Management Sciences 18 (2007), 17-35.

[24] R. Lal, and R. Staelin, An approach for developing an optimal discount pricing policy, Management Science 30(1984), 1524-1539.

[25] Z. K. Weng and R. T. Wong, General models for the supplier's all-nit quantity discount policy, Naval Research Logistics 40 (1993), 971-991.

[26] Y. C. Shiue, An inventory model for perishable items in a lot-size system with quantity discounts, European Journal of Operational Research 45 (1990), 260-264.

[27] T. H. Burwell, D. S. Dave, K. E. Fitzpatrick and M. R. Roy, Economic lot size model for price-depend demand under quantity and freight discount, International Journal of Production Economics 48(1997), 141-155.

[28] H. M. Wee, Deteriorating inventory model with quantity discount, pricing and partial backlogging, International Journal of Production Economics 59 (1999), 511-518.

[29] S. Papachristos and K. Skouri, An inventory model with deteriorating items, quantity discount, pricing and time-dependent partial backlogging, International Journal of Production Economics 83 (2003), 247-256.

[30] P. M. Ghare and G. H. Schrader, A model for exponentially decaying inventory system, The Journal of Industrial Engineering 163 (1963), 238-243.

[31] R. P. Covert, and G. C. Philip, An EOQ model for items with Weibull distribution deterioration, AIIE Transactions 5 (1973), 323-326.

[32] G. C. Philip, A generalized EOQ model for items with Weibull distribution, AIIE Transactions 6 (1974), 159-162. 
[33] N. H. Shah, An order-level lot size inventory model for deteriorating items, AIIE Transactions 9 (1977), 108-112.

[34] S. K. Goyal and B. C. Giri, Recent trends in modeling of deteriorating inventory, European Journal of Operational Research 134 (2001), 1-6.

[35] I. Moon, B. C. Giri and B. Ko, Economic order quantity models for ameliorating/deteriorating items under inflation and time discounting, European Journal of Operational Research 162 (2005), 773-785.

[36] P. S. Deng, R. H. Lin and P. Chu, A note on the inventory models for deteriorating items with ramp type demand rate, European Journal of Operational Research 178 (2007), 112 120.

[37] J. J. Liao, A note on an EOQ model for deteriorating items under supplier credit linked to ordering quantity, Applied Mathematical Modeling 31 (2007), 1690-1699.

Department of Management Sciences and Decision Making, Tamkang University, Tamsui, Taipei 251, Taiwan, R.O.C.

E-mail: liangyuh@mail.tku.edu.tw

Department of Industrial Engineering \& Management, Ching Yun Unversity, Jung-Li, Taoyuan 320, Taiwan, R.O.C.

E-mail: ctyang@cyu.edu.tw

Graduate Institute of Management Sciences, Tamkang University, Tamsui, Taipei 251, Taiwan, R.O.C.

E-mail: yansf@mail.tku.edu.tw 